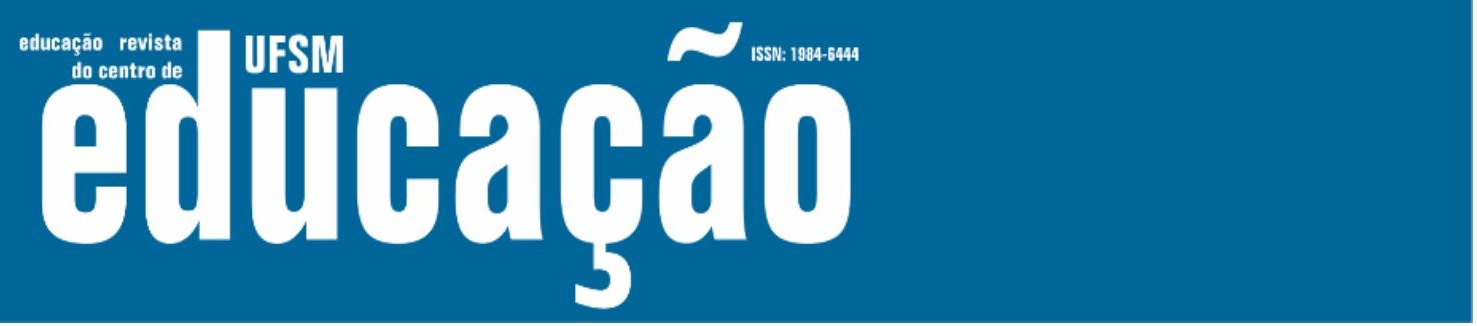

ISSN: 1984-6444 | http://dx.doi.org/10.5902/1984644444454

\title{
Educação em Direitos Humanos e Educação Intercultural: apontamentos e aproximações freireanas
}

\author{
Education in Human Rights and Intercultural Education: \\ freirean notes and approaches
}

\begin{abstract}
Márcia Maria Rodrigues Uchôa
Professora e Pesquisadora nas áreas de Currículo, Interculturalidade e Fronteiras. Pós-doutoranda do Programa de Pós-Graduação em Educação: Currículo da Pontifícia Universidade Católica de São Paulo, São Paulo, Brasil.

profa.uchoa@gmail.com - http://orcid.org/0000-0003-0939-5646
\end{abstract}

Recebido em 22 de maio de 2020

Aprovado em 13 de outubro de 2020

Publicado em 30 de setembro de 2021

\section{RESUMO}

O artigo tem como objetivo delinear as peculiaridades da Educação em Direitos Humanos e da Educação Intercultural, ao mesmo tempo em que busca estabelecer suas convergências através da pedagogia freireana. Trata-se de uma pesquisa de cunho bibliográfico, com aporte teórico em documentos da Organização das Nações Unidas - ONU (1948, 1966a, 1966b, 1993) e da Organização das Nações Unidas para a Educação, Ciência e Cultura - Unesco (2002, 2006), dos teóricos Boaventura de Sousa Santos (2014), Vera Maria Candau (2013), Paulo Freire (1987, 1999, 2011), entre outros. A Educação em Direitos Humanos e a Educação Intercultural constituemse em um projeto educacional democrático, includente e libertador, que, materializado no currículo, aponta perspectivas para a equidade social. Espera-se que o trabalho possa contribuir para a ampliação do debate acerca de uma educação cidadã, que reconheça e valorize as diferenças e a diversidade.

Palavras-chave: Educação em Direitos Humanos; Educação Intercultural; Currículo; Pedagogia freireana.

\section{ABSTRACT}

The article aims to outline the peculiarities of Education in Human Rights and Intercultural Education, at the same time that it seeks to establish their convergences through freirean Pedagogy. This is a bibliographic research, with theoretical support in documents from the United Nations - UN (1948, 1966a, 1966b, 1993) and the United Nations Educational, Scientific and Cultural Organization - Unesco (2002, 2006), theorists Boaventura de Sousa Santos (2014), Vera Maria Candau (2013), Paulo Freire $(1987,1999,2011)$, among others. Education in Human Rights and Intercultural 


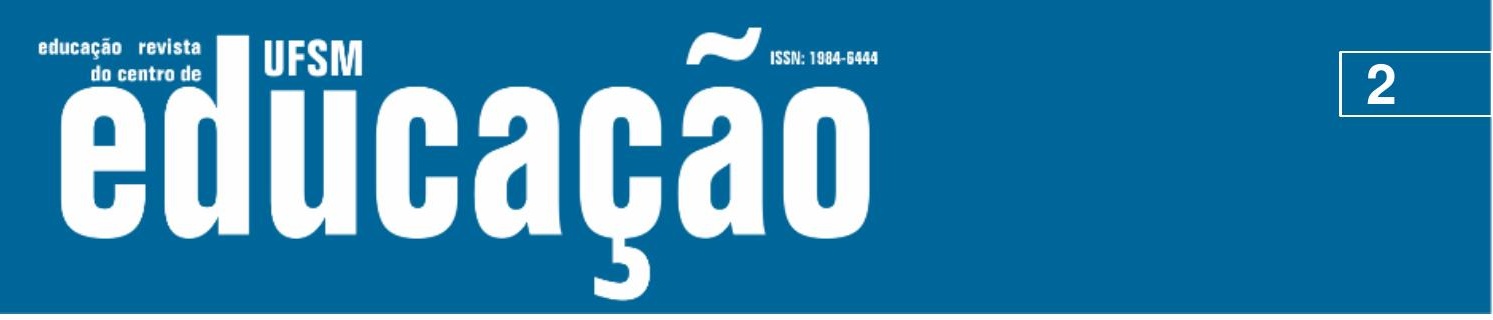

ISSN: 1984-6444 | http://dx.doi.org/10.5902/1984644444454

Education constitute a democratic, inclusive and liberating educational project, which materialized in the curriculum points to perspectives for social equity. It is hoped that the work can contribute to the broadening of the debate about citizen education, which recognizes and values differences and diversity.

Keywords: Human Rights Education; Intercultural Education; Curriculum; Freirean pedagogy.

\section{Introdução}

Os direitos humanos visam à garantia da dignidade humana, observados os diversos aspectos inerentes à vida em sua totalidade. Ao longo da história, vários eventos ocorridos demonstraram a preocupação com a proteção da dignidade humana, mas, foi com a Declaração Universal dos Direitos Humanos (DUDH), aprovada pela Organização das Nações Unidas, em 1948, que esta pauta ganhou preocupação internacional.

A Educação em Direitos Humanos pretende o desenvolvimento de uma cultura de paz entre os diferentes povos, sociedades e culturas, o fortalecimento das instituições democráticas e a garantia da dignidade humana, considerando a vida na sua totalidade.

Analogamente, a Educação Intercultural, ao afirmar a diferença como riqueza cultural e ao valorizar o diálogo entre os diferentes sujeitos (individuais e coletivos), constitui-se em uma proposta educacional voltada para a construção de identidades plurais, para a democratização do saber e para o desenvolvimento da justiça social.

Nosso objetivo, neste trabalho, é contextualizar e caracterizar a Educação em Direitos Humanos e a Educação Intercultural, entendo-as como conquistas de processos de lutas e não como dados históricos. Evidenciaremos suas particularidades e objetivos, ao mesmo tempo em que reconhecemos, na pedagogia freireana, a intersecção entre ambos os projetos educacionais.

O artigo está dividido em cinco partes: na primeira apresentamos os Direitos Humanos na contemporaneidade e os seus marcos históricos; na segunda parte, abordamos a Educação em Direitos Humanos no cenário internacional e os seus desdobramentos no Brasil; na terceira, destacamos a Educação Intercultural, partindo 


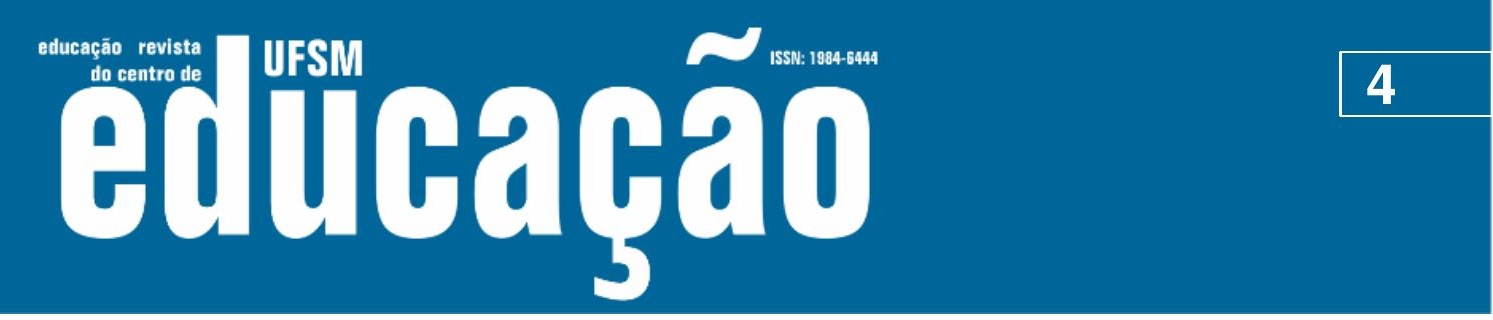

ISSN: 1984-6444 | http://dx.doi.org/10.5902/1984644444454

Já o Pacto Internacional dos Direitos Econômicos, Sociais e Culturais apresenta direitos orientados para a segurança e bem-estar dos indivíduos, incluindo direitos: à educação; ao trabalho; à alimentação; à habitação; à saúde etc. (ONU, 1966b). Para que tais direitos sejam positivados é preciso que haja um esforço e comprometimento dos Estados, desempenhando ações afirmativas na vida dos indivíduos.

Este Pacto reconhece, no seu Artigo 13, o direito de toda pessoa à educação. Os Estados-Nações concordam que

[...] a educação deverá capacitar todas as pessoas a participar efetivamente de uma sociedade livre, favorecer a compreensão, a tolerância e a amizade entre todas as nações e entre todos os grupos raciais, étnicos ou religiosos e promover as atividades das Nações Unidas em prol da manutenção da paz (ONU, 1966b, p. 6).

Ao longo da história, várias agências das Nações Unidas foram criadas com o objetivo de defender os Direitos Humanos, além de organismos internacionais, dentre eles: Fundo das Nações Unidas para a Infância (Unicef); Organização das Nações Unidas para a Educação, Ciência e Cultura (Unesco); Anistia Internacional; Alto Comissário das Nações Unidas para os Direitos Humanos (ACNUDH); Alto Comissariado das Nações Unidas para Refugiados (Acnur); Serviço Paz e Justiça na América Latina (Serpaj-AL), além de outros.

No ano de 2002, a Unesco proclamou a Declaração Universal sobre a Diversidade Cultural, reafirmando o seu compromisso com a DUDH de 1948 e reconhecendo em seu preâmbulo, a cultura como centro do debate contemporâneo sobre as identidades e:

Afirmando que o respeito à diversidade das culturas, à tolerância, ao diálogo e à cooperação, em um clima de confiança e de entendimento mútuos, estão entre as melhores garantias da paz e da segurança internacionais, Aspirando a uma maior solidariedade fundada no reconhecimento da diversidade cultural, na consciência da unidade do gênero humano e no desenvolvimento dos intercâmbios culturais, [...] (UNESCO, 2002). 


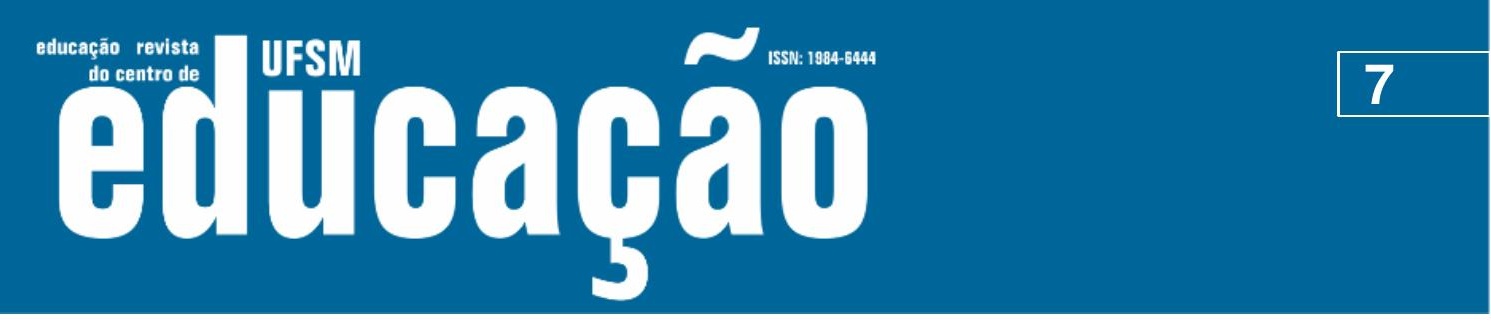

ISSN: 1984-6444 | http://dx.doi.org/10.5902/1984644444454

1993, em Viena - Áustria, que resultou na aprovação da Declaração e Programa de Ação de Viena, com apresentações efetivas de práticas educacionais para a questão dos direitos humanos. Constam no documento, vários artigos, dos quais destacamos dois:

33. A Conferência Mundial sobre Direitos Humanos reafirma que os Estados estão vinculados, conforme previsto na Declaração Universal dos Direitos do Homem, no Pacto Internacional sobre os Direitos econômicos, Sociais e Culturais e noutros instrumentos internacionais de Direitos Humanos, a garantir que a educação se destine a reforçar o respeito pelos Direitos Humanos e liberdades fundamentais. A Conferência Mundial sobre Direitos Humanos realça a importância de incluir a questão dos Direitos Humanos nos programas de educação e apela aos Estados para o fazerem. A educação deverá promover a compreensão, a tolerância, a paz e as relações amistosas entre as nações e todos os grupos raciais ou religiosos, e encorajar 0 desenvolvimento de atividades das Nações Unidas na prossecução destes objetivos. Assim, a educação em matéria de Direitos Humanos e a divulgação de informação adequada, tanto teórica como prática, desempenham um papel importante na promoção e no respeito dos Direitos Humanos em relação a todos os indivíduos, sem distinção de qualquer tipo, nomeadamente de raça, sexo, língua ou religião, devendo isto ser incluído nas políticas educacionais, quer a nível nacional, quer internacional. A Conferência Mundial sobre Direitos Humanos observa que as limitações de recursos e a falta de adequação das instituições podem impedir a imediata concretização destes objetivos (ONU, 1993, p. 9, grifos nossos).

80. A educação em matéria de Direitos Humanos deverá incluir a paz, a democracia, o desenvolvimento e a justiça social, conforme definidos nos instrumentos internacionais e regionais de Direitos Humanos, a fim de alcançar uma compreensão e uma consciencialização comuns, que permitam reforçar o compromisso universal em favor dos Direitos Humanos (ONU, 1993, p. 20, grifos nossos).

Nesse sentido reconhece-se com a Conferência Mundial de Viena, a importância da Educação para o desenvolvimento de uma cultura mundial de direitos humanos, pela promoção da paz, pelo debate e pelo respeito aos diferentes povos, sem distinção de qualquer natureza, ao tempo em que afirma o compromisso dos Estados em incluir nos seus programas educacionais a questão dos Direitos Humanos.

Em consequência da Declaração e Programa de Ação de Viena, a Organização das Nações Unidas instituiu a década da Educação em Direitos Humanos entre 1995 e 2004, ao término desse período lançou o Programa Mundial para Educação em Direitos Humanos (PMEDH), em duas fases: a primeira de 2005 a 2009, que 


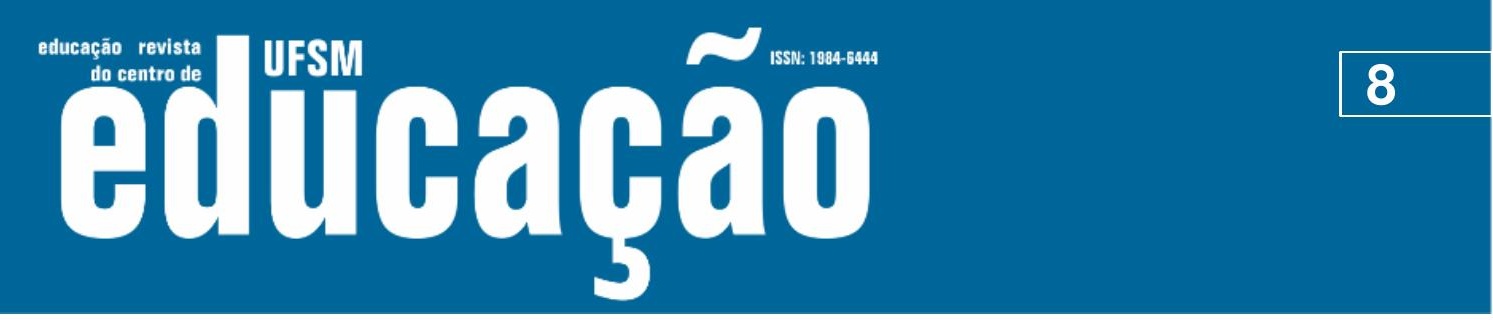

ISSN: 1984-6444 | http://dx.doi.org/10.5902/1984644444454

apresentou recomendações, referências e metas direcionadas para a Educação Básica; a segunda fase do programa, de 2010 a 2014, foi voltada ao Ensino Superior, para a formação de professores e de profissionais dos sistemas de segurança e justiça.

No PMEDH constam as seguintes implicações e concepção de uma educação em direitos humanos.

\begin{abstract}
A educação em direitos humanos pode ser definida como um conjunto de atividades de educação, de capacitação e de difusão de informação, orientadas para criar uma cultura universal de direitos humanos. Uma educação integral em direitos humanos não somente proporciona conhecimentos sobre os direitos humanos e os mecanismos para protegêlos, mas que, além disso, transmite as aptidões necessárias para promover, defender e aplicar os direitos humanos na vida cotidiana. A educação em direitos humanos promove as atitudes e o comportamento necessários para que os direitos humanos de todos os membros da sociedade sejam respeitados (UNESCO, 2006, p. 6, grifos nossos).
\end{abstract}

Pautados no documento, podemos concluir que a Educação em Direitos Humanos nos remete ao cotidiano, aos direitos civis, políticos, sociais, econômicos e culturais de todos os indivíduos. Ela pretende uma educação para e pela cidadania e convoca-nos a lutar pela democracia, lidar com os conflitos decorrentes do convívio nos espaços plurais e a ter atitudes de respeito, orientadas pelo princípio da alteridade.

\title{
Os Direitos Humanos no Brasil
}

O debate acerca dos Direitos Humanos no Brasil é recente, começa em 1985, após os 21 anos do Regime Ditatorial Militar e tem como marco a aprovação da Constituição Federal de 1988, que firma o pacto com a DUDH (ONU, 1948), reforçando a valorização da dignidade humana.

A Constituição Cidadã de 1988 resultou da luta de vários organismos e movimentos que atuaram conjuntamente para o estabelecimento do Estado Democrático de Direitos, anulados na Ditadura Militar, período marcado por atos de violências, protagonizados pelo Estado nacional, como: torturas, mortes, 


\section{Tusm Aillathá

ISSN: 1984-6444 | http://dx.doi.org/10.5902/1984644444454

A Educação em Direitos Humanos é um processo em curso no país, haja vista, que mesmo com a aprovação do PNEDH (BRASIL, 2007) e suas reformulações ao longo dos anos, ainda há uma luta para sua implementação, sobretudo, na atualidade, com a ascensão ao poder de um governo de extrema direita que possui uma pauta deliberada de oposição aos Direitos Humanos, o que se materializou com: a extinção de vários Conselhos no ano de 2019, que arrefeceu a democracia participativa nas políticas públicas e os seus discursos autoritários, negando a história e reforçando o senso comum de que "os direitos humanos é um projeto de esquerda em defesa de bandidos". Em decorrência do nefasto cenário que vivemos no país, mais do que nunca a Educação em Direitos Humanos é uma pauta a ser lutada e defendida em todos os espaços sociais, notadamente, nos espaços educacionais, tendo em vista uma formação cidadã, que acolhe e respeita as diferenças e a diversidade, pela empatia ao Outro.

\section{A Educação Intercultural materializada no currículo}

Em conformidade com Fidel Tubino (2016), professor da Pontifícia Universidade Católica do Peru e coordenador da Rede Internacional de Estudos Interculturais (Ridei), a Educação Intercultural surge na América Latina relacionada à educação bilíngue dos povos indígenas, consequentemente está envolvida por um viés linguístico e indigenista, tendo a superação dos estigmas tribais como o seu maior desafio na atualidade.

A educação intercultural, a qual é marcada pelo diálogo horizontal entre as várias culturas que permeiam o ambiente educacional, tem como ponto partida, a identificação das causas do não diálogo, ou seja, é necessário problematizar as razões que provocaram a hierarquização, a invisibilidade das populações marginalizadas e os seus papéis sociais.

A partir dessa perspectiva, o diálogo intercultural implica em reconhecer sem pré-julgar, as diversas concepções de mundo e hierarquias de valores que estão em jogo. Dessa forma, implica em reconhecer as diversas sensibilidades e espiritualidades, que pessoas, de diferentes horizontes culturais, possuem.

$[\ldots]$ 


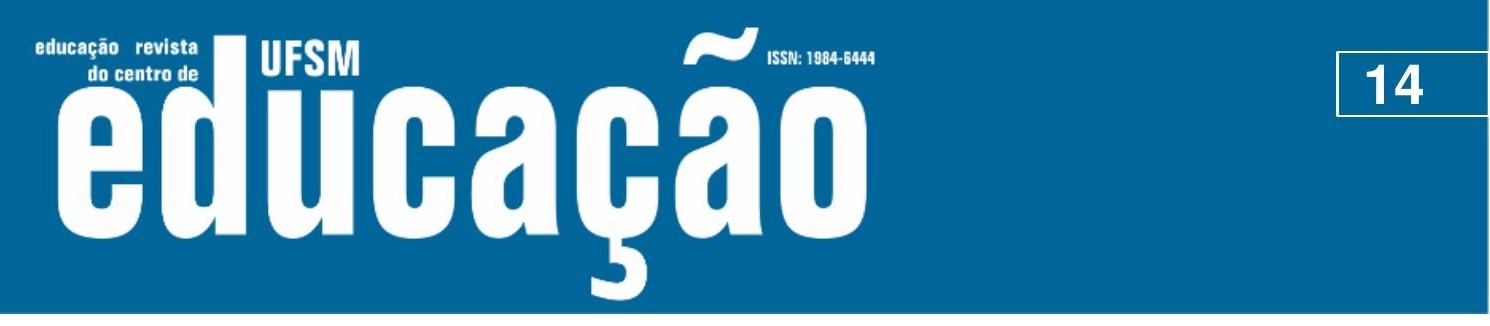

ISSN: 1984-6444 | http://dx.doi.org/10.5902/1984644444454

A formação para o diálogo e a deliberação intercultural na educação devem promover nos educandos, a visibilização dos estigmas e "projeções", a partir das quais percebem e se relacionam com o "outro". Esse é o ponto de partida (TUBINO, 2016, p. 30, grifos do autor).

Nesse sentido, professores e alunos devem reconhecer que o legítimo diálogo intercultural pressupõe a ausência dos estigmas e a manifestação de afinidades compartilhadas, para isso é preciso evitar a folclorização das culturas, que reduz, limita e apresenta uma visão superficial das manifestações culturais, ocultando as subjetividades presentes nessas culturas (TUBINO, 2016).

$\mathrm{Na}$ legislação brasileira, a Educação Intercultural surge também associada à educação dos povos indígenas, a Lei de Diretrizes e Bases da Educação Nacional n.. 9.394/96 explicita:

Art. 78. O Sistema de Ensino da União, com a colaboração das agências
federais de fomento à cultura e de assistência aos índios, desenvolverá
programas integrados de ensino e pesquisa, para oferta de educação escolar
bilíngue e intercultural aos povos indígenas, com os seguintes objetivos:
I - proporcionar aos índios, suas comunidades e povos, a recuperação de
suas memórias históricas; a reafirmação de suas identidades étnicas; a
valorização de suas línguas e ciências;
II - garantir aos índios, suas comunidades e povos, o acesso às informações,
conhecimentos técnicos e científicos da sociedade nacional e demais
sociedades indígenas e não índias. Art. 79. A União apoiará técnica e financeiramente os sistemas de ensino no provimento da educação intercultural às comunidades indígenas, desenvolvendo programas integrados de ensino e pesquisa.

$\S 1^{\circ}$ Os programas serão planejados com audiência das comunidades indígenas.

$\S 2$ - Os programas a que se refere este artigo, incluídos nos Planos Nacionais de Educação, terão os seguintes objetivos:

I - fortalecer as práticas socioculturais e a língua materna de cada comunidade indígena;

II - manter programas de formação de pessoal especializado, destinado à educação escolar nas comunidades indígenas;

III - desenvolver currículos e programas específicos, neles incluindo os conteúdos culturais correspondentes às respectivas comunidades;

IV - elaborar e publicar sistematicamente material didático específico e diferenciado (BRASIL, 2017, p. 49-50, grifos nossos).

Destarte, há que se ampliar as discussões acerca da Educação Intercultural no Estado nacional, a partir de políticas públicas que reconheçam e valorizem a realidade multicultural do país, o contexto de fronteira com os países sul-americanos e a 


\section{U usm outlatato}

ISSN: 1984-6444 | http://dx.doi.org/10.5902/1984644444454

miscigenação étnica como marca identitária do povo brasileiro, com desdobramentos nas práticas curriculares.

A pesquisadora Daniela Valentim coloca-se a favor da interculturalidade, pois ao tempo em que fortalece a formação de identidades dinâmicas e plurais, questiona a visão essencializada de sua constituição. Para a autora, a interculturalidade potencializa o processo de empoderamento dos sujeitos inferiorizados e marginalizados, ao mesmo tempo em que "estimula os processos de construção da autonomia num horizonte de emancipação social, de construção de sociedades onde sejam possíveis relações igualitárias entre diferentes sujeitos e atores socioculturais" (2016, p. 147).

A educação intercultural, ao abrir espaços para a manifestação das diferenças e da diversidade cultural, constitui-se em uma proposta humanitária e um caminho para a garantia de direitos humanos básicos.

Uchôa (2019) apresenta, a partir da metodologia da trama conceitual ${ }^{1}$, o Currículo em uma perspectiva de Interculturalidade, pela articulação dialética e recíproca com outros conceitos, explicitada na Figura 1. 


\section{Ailfbapẫ \\ ,}

ISSN: 1984-6444 | http://dx.doi.org/10.5902/1984644444454

Figura 1 - Trama Conceitual centrada no Currículo Intercultural

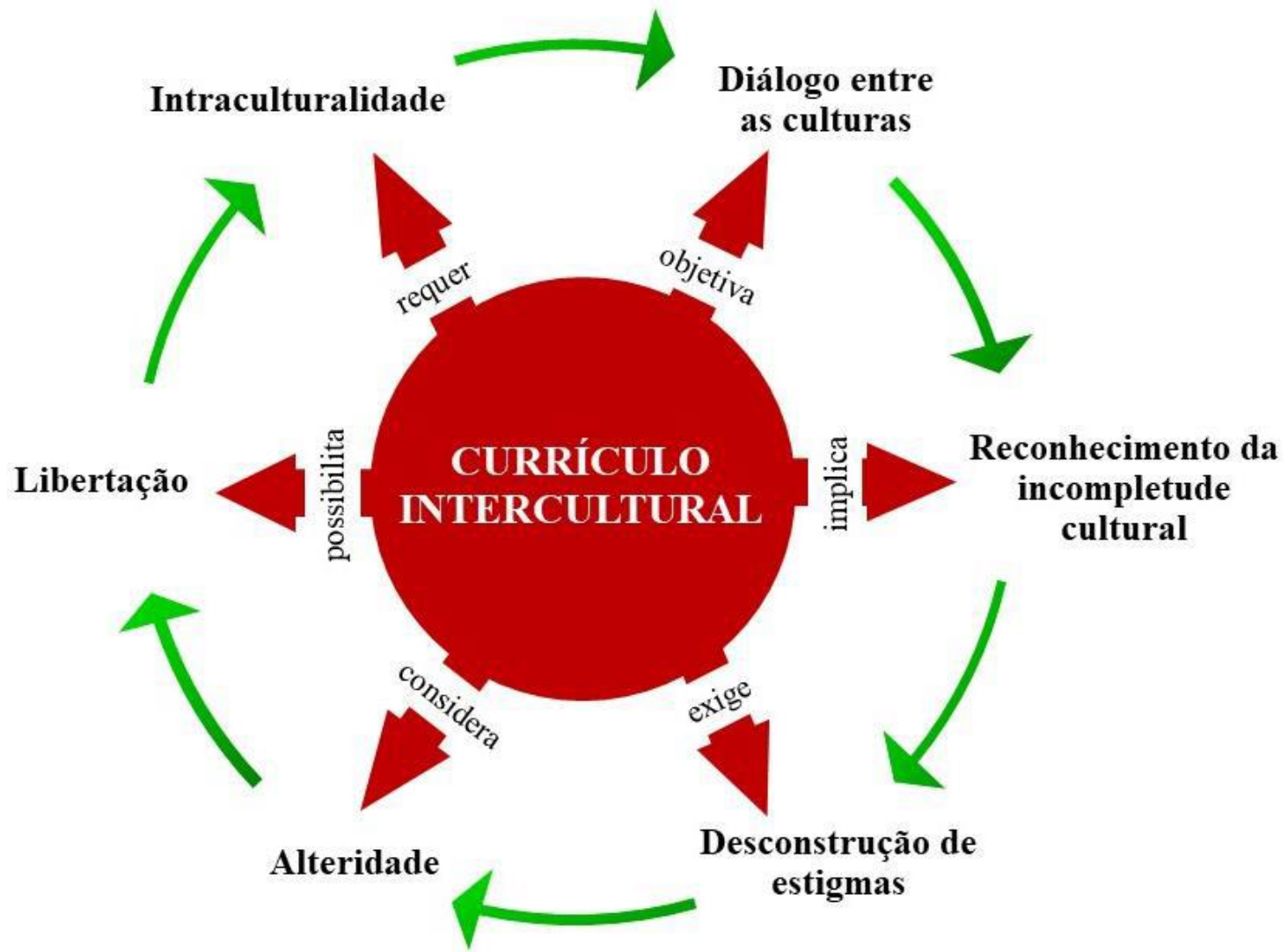

Fonte: Uchôa (2019, p. 101).

A figura 1 traz o Currículo Intercultural como centro da explicitação esquemática, articulado a outros conceitos e significados, que explanam: demanda, objetivo, implicação, exigência, consideração e possibilidade de uma Educação Intercultural.

Assim, a perspectiva intercultural no currículo: a) requer a intraculturalidade, isto é, o adentramento na própria cultura, o conhecimento dos processos constitutivos culturais e a apropriação do arbitrário cultural, em vista do empoderamento e construção da identidade dos/as sujeitos/as socioculturais; b) objetiva o diálogo entre as culturas inseridas no contexto escolar, sob uma ótica freireana, com horizontalidade, que não subordina e nem hierarquiza os saberes; c) implica o reconhecimento da incompletude cultural, isto é, ao reconhecer que nenhuma cultura é completa e suficiente, o diálogo surge como uma estratégia de interação, conhecimento e aprendizagem mútua; d) exige a desconstrução de estigmas, que são 


\section{N-Tis

ISSN: 1984-6444 | http://dx.doi.org/10.5902/1984644444454

A perspectiva intercultural que defendo quer promover uma educação para o reconhecimento do "outro", para o diálogo entre os diferentes grupos sociais e culturais. Uma educação para a negociação cultural, que enfrenta os conflitos provocados pela assimetria de poder entre os diferentes grupos socioculturais nas nossas sociedades e é capaz de favorecer a construção de um projeto comum, pelo qual as diferenças sejam dialeticamente incluídas (CANDAU, 2013, p. 23).

Para Candau e Leite (2006) a perspectiva intercultural ganha materialidade na pedagogia freireana, pois o reconhecimento do repertório cultural do educando não é tão somente uma estratégia metodológica, mas é

[...] um modo de lidar com a diferença cultural que se aproxima daquele atualmente proposto pela perspectiva multi/intercultural: mais do que um respeito distante e asséptico por essa diferença, mais do que tolerância, enfatiza-se e estimula-se a troca entre os sujeitos das relações pedagógicas. [...] (CANDAU; LEITE, 2006, p. 7).

Para compreender as particularidades da abordagem cultural em Paulo Freire, as autoras destacam que é imperioso explorar o conceito de cultura com o qual trabalha, que é vinculado a toda produção humana.

Similarmente, Candau e Russo destacam Freire como pioneiro da perspectiva intercultural, de modo que suas contribuições se constituem "uma das referências ineludíveis das buscas de construção de propostas educativas que tenham presente os diferentes contextos socioculturais e o diálogo entre diversos saberes" (2010, p. 162).

Paulo Freire tem a cultura como ponto de partida do processo educacional dos sujeitos, suas práticas pedagógicas nos Círculos de Cultura, em Angicos - Rio Grande do Norte, no ano de 1963, demonstraram que as experiências dos educandos são basilares para a sua tomada de consciência e libertação, a partir do reconhecimento enquanto sujeito histórico e social e das suas condições existenciais.

Assim, temos em Freire (1999) que sem a conscientização é impossível uma formação ética libertadora, daí a importância de o educador proporcionar o deslocamento da consciência ingênua do sujeito para uma consciência ético-crítica, a partir do seu contexto e mudando sua própria realidade. 


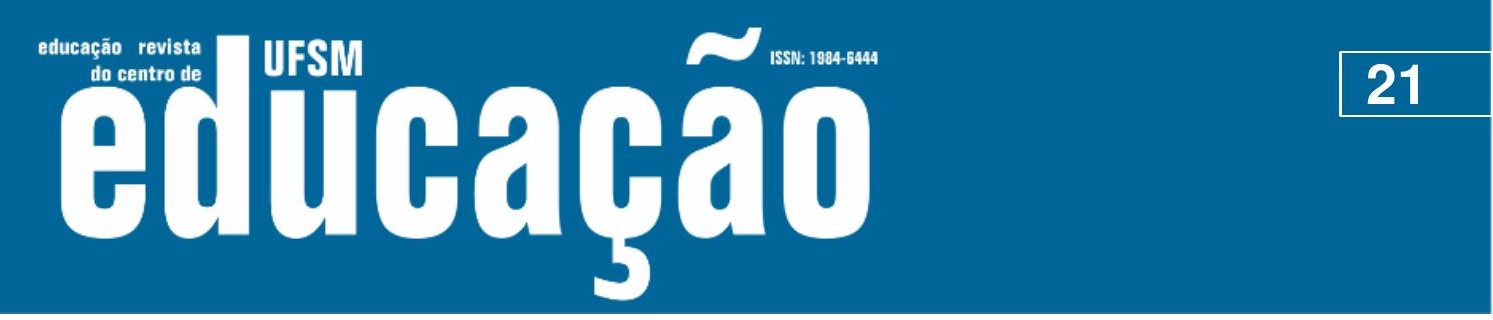

ISSN: 1984-6444 | http://dx.doi.org/10.5902/1984644444454

Quanto mais crítico um grupo humano, tanto mais democrático e permeável, em regra. Tanto mais democrático, quanto mais ligado às condições de sua circunstância. Tanto menos experiências democráticas que exigem dele o conhecimento crítico de sua realidade, pela participação nela, pela sua intimidade com ela, quanto mais superposto a essa realidade e inclinado a formas ingênuas de encará-la. A formas ingênuas de percebê-las. A formas verbosas de representá-la. Quanto menos criticidade em nós, tanto mais ingenuamente tratamos os problemas e discutimos superficialmente os assuntos (FREIRE, 1999, p. 95-96).

$\mathrm{O}$ ato pedagógico que se constrói na dialogicidade e no despertar de uma consciência crítica, originária dos próprios oprimidos, materializa-se em uma práxis de transformação, destarte, de libertação dos sujeitos.

Pela conscientização, transformação e libertação dos sujeitos, temos em Freire o encontro de uma educação democrática e cidadã, por isso mesmo, de uma Educação em Direitos Humanos com uma Educação Intercultural, que se converge em um currículo intercultural e se apresenta como uma proposta que rompe e transcende a colonialidade histórica impregnada nas sociedades latino-americanas, que hierarquiza e subordina o poder e o saber.

\section{Considerações finais}

Por decreto irrevogável fica estabelecido o reinado permanente da justiça e da claridade,

e a alegria será uma bandeira generosa para sempre desfraldada na alma do povo (MELLO, 1964).

O poeta amazonense Thiago de Mello, em 1964, publicou o poema "Os Estatutos do Homem", durante o período em que esteve exilado no Chile, em consequência da Ditadura Militar no Brasil (1964-1985). Essa narrativa, que expressa os desejos do poeta, remete-nos a pensar em ideais democráticos de liberdade e justiça, pelo seu conteúdo, mas também em leis e decretos, pela sua forma.

A obra poética traz consigo leveza e estética singulares, propícia ao estudo de temáticas sérias e pontuais, como a que nos propomos discutir neste texto, a Educação em Direitos Humanos e a Educação Intercultural, interseccionada na pedagogia freireana, haja vista que o desenvolvimento de uma cultura de direitos 


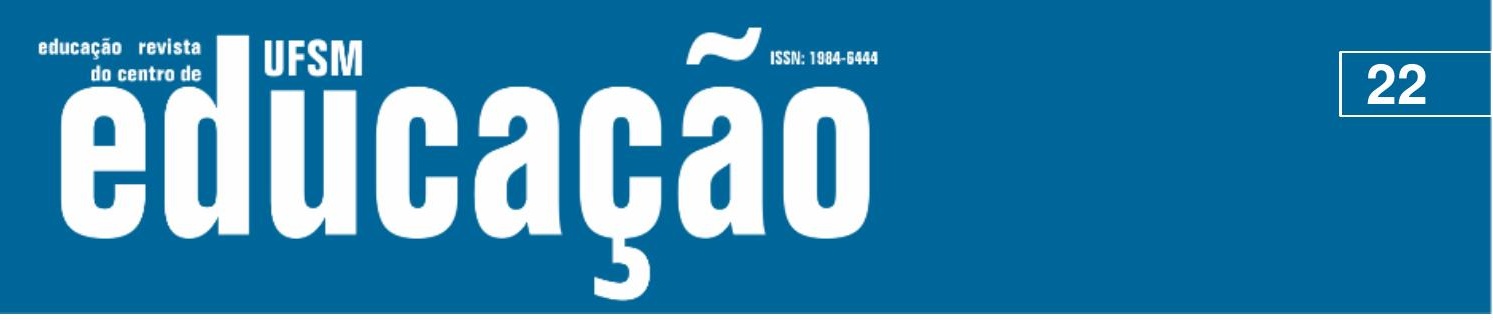

ISSN: 1984-6444 | http://dx.doi.org/10.5902/1984644444454

humanos, voltada para o exercício da cidadania, de respeito às diferenças e à diversidade cultural, exige o desenvolvimento da empatia.

A Educação em Direitos Humanos pauta-se na afirmação dos direitos humanos como indivisíveis e interdependentes, em vista da construção de uma sociedade baseada na equidade social, no respeito à diversidade e na consolidação de uma cultura democrática e cidadã.

A Educação Intercultural, em similitude, ao propor o diálogo horizontal entre as diversas culturas e afirmar o valor positivo das diferenças, constitui-se em uma proposta humanitária e um caminho para a garantia de direitos humanos básicos.

Por conseguinte, a pedagogia freireana, que agrega ambas as pautas supracitadas, converge-se em um projeto formativo humano, que reverbera na transformação social, pela tomada de consciência e libertação dos sujeitos, enquanto seres históricos e sociais.

Por fim, a luta por uma educação democrática e inclusiva, pautada na concretização dos direitos humanos e na interculturalidade curricular, deve fazer parte de um empreendimento coletivo, uma vez que abre perspectivas para fazer avançar a justiça social, ao considerar e respeitar a alteridade e promover a libertação dos sujeitos.

\section{Referências}

APPLE, Michael; AU, Wayne; GANDIN, Luís Armando. O mapeamento da educação crítica. In: APPLE, Michael; AU, Wayne.; GANDIN, Luís Armando (Orgs.). Educação crítica: análise internacional. Porto Alegre: Artmed, 2011. p. 14-32.

BOBBIO, Norberto. A era dos direitos. Rio de Janeiro: Elsevier, 2004.

BRASIL. Decreto n.o 1.904, de 13 de maio de 1996. 1996. Institui o Programa Nacional de Direitos Humanos - PNDH. Disponível em: https://www2.camara.leg.br/legin/fed/decret/1996/decreto-1904-13-maio-1996431671-publicacaooriginal-1-pe.html. Acesso em: 14 maio 2020.

BRASIL. Comitê Nacional de Educação em Direitos Humanos. Plano Nacional de Educação em Direitos Humanos. Brasília: Secretaria Especial dos Direitos Humanos, Ministério da Educação, Ministério da Justiça, Unesco, 2007. 


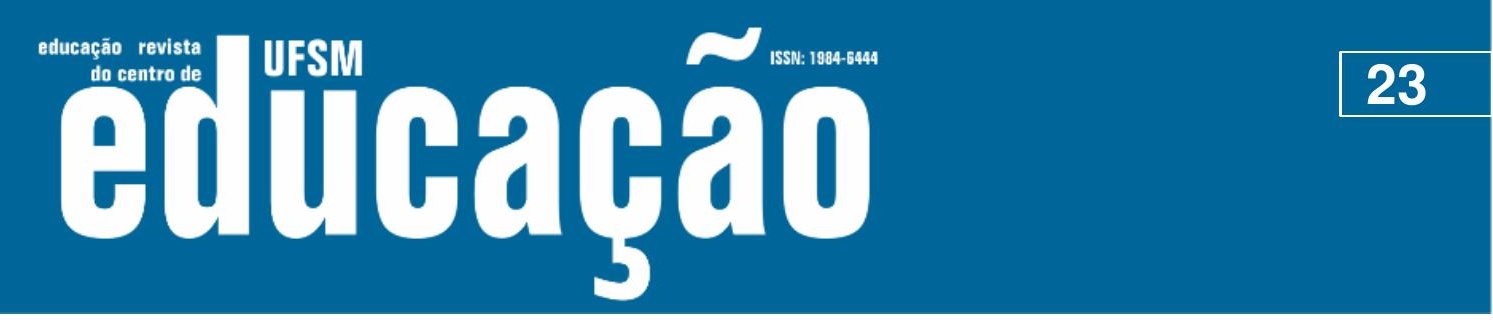

ISSN: 1984-6444 | http://dx.doi.org/10.5902/1984644444454

BRASIL. LDB - Lei de Diretrizes e Bases da Educação Nacional. Brasília: Senado Federal, Coordenação de Edições Técnicas, 2017.

CANDAU, Vera Maria. Multiculturalismo e educação: desafios para a prática pedagógica. In: MOREIRA, Antonio Flávio; CANDAU, Vera Maria (Orgs.). Multiculturalismo: diferenças culturais e práticas pedagógicas. 10. ed. Petrópolis, RJ: Vozes, 2013. p. 13-37.

CANDAU, Vera Maria; LEITE, Miriam S. Diálogos entre diferença e educação. In: CANDAU, Vera Maria (Org.). Educação intercultural e cotidiano escolar. Rio de Janeiro: 7 Letras, 2006. p. 121-39.

CANDAU, Vera Maria; RUSSO, Kelly. Interculturalidade e educação na América Latina: uma construção plural, original e complexa. Revista Diálogo Educacional, Curitiba, vol. 10, n. 29, p. 151-69, jan./abr., 2010. Disponível em: https://periodicos.pucpr.br/index.php/dialogoeducacional/article/view/3076. Acesso em: 10 jul. 2017.

CASALI, Alípio. Direitos humanos e diversidade cultural: implicações curriculares. R. Educ. Pública, Cuiabá v. 25 n. 65/2, p. 549-572, maio/ago. 2018. Disponível em: http://periodicoscientificos.ufmt.br/ojs/index.php/educacaopublica/article/view/6883.

Acesso em: 11 set. 2019.

FREIRE, Paulo. Pedagogia do oprimido. 17. ed. Rio de Janeiro: Paz e Terra, 1987.

FREIRE, Paulo. Educação como Prática de Liberdade. 23. ed. São Paulo: Paz e Terra, 1999.

FREIRE, Paulo. Pedagogia da autonomia: saberes necessários à prática educativa. São Paulo: Paz e Terra, 2011.

MCLAREN, Peter. Multiculturalismo revolucionário: pedagogia do dissenso para o novo milênio. Porto Alegre: Artes Médicas Sul, 2000.

MELLO, Thiago de. Os estatutos do homem. Disponível em: https://www.escritas.org/pt/t/12844/os-estatutos-do-homem. Acesso em: 18 maio 2020.

ONU. Declaração Universal dos Direitos Humanos. 1948. Disponível em: http://www.onu.org.br/img/2014/09/DUDH.pdf. Acesso em: 26 mar. 2018.

ONU. Pacto Internacional dos Direitos Civis e Políticos. 1966a. Disponível em: https://www.oas.org/dil/port/1966\%20Pacto\%20Internacional\%20sobre\%20Direitos\% 20Civis\%20e\%20Pol\%C3\%ADticos.pdf. Acesso em: 4 out. 2019. 


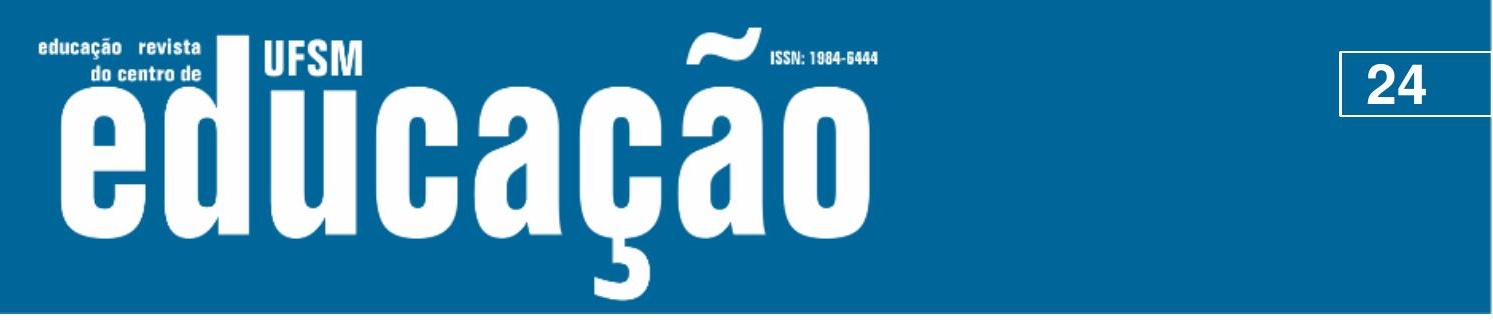

ISSN: 1984-6444 | http://dx.doi.org/10.5902/1984644444454

ONU. Pacto Internacional dos Direitos Econômicos, Sociais e Culturais. 1966b. Disponível

em: https://www.oas.org/dil/port/1966\%20Pacto\%20Internacional\%20sobre\%20os\%20Dir eitos\%20Econ\%C3\%B3micos,\%20Sociais\%20e\%20Culturais.pdf. Acesso em: 4 out. 2019.

ONU. Declaração e Programa de Ação de Viena. Conferência Mundial sobre Direitos Humanos. $1993 . \quad$ Disponível em: https://www.oas.org/dil/port/1993\%20Declara\%C3\%A7\%C3\%A30\%20e\%20Program a\%20de\%20Ac\%C3\%A7\%C3\%A30\%20adoptado\%20pela\%20Confer\%C3\%AAncia \%20Mundial\%20de\%20Viena\%20sobre\%20Direitos\%20Humanos\%20em\%20junho \%20de\%201993.pdf. Acesso em: 6 maio 2020.

SANTOS, Boaventura de Sousa. Direitos humanos: ilusões e desafios. In: SANTOS, Boaventura de Sousa; CHAUI, Marilena. Direitos Humanos, Democracia e Desenvolvimento. São Paulo: Cortez, 2014. p. 31-85.

SAUL, Ana Maria; SAUL, Alexandre. Referenciais freireanos: o projeto político pedagógico e a formação de educadores. 2014. Disponível em: http://eadconsultoria.moodlelivre.com/file.php/1/palestras/ArtigoReferenciaisFreirean osParaPPP.pdf. Acesso em: 08 maio 2017.

TUBINO, Fidel. Porque a formação cidadã é necessária na educação intercultural. In: CANDAU, Vera Maria (Org.). Interculturalizar, descolonizar, democratizar: uma educação "outra"? Rio de Janeiro: 7 Letras, 2016. p. 22-36.

UCHÔA, Márcia Maria Rodrigues Uchôa. Currículo Intercultural na Fronteira: um estudo sobre a Política e as Práticas de Currículo na fronteira Brasil/Bolívia do estado de Rondônia. Orientador: Alípio Márcio Dias Casali. 2019. 163f. Tese (Doutorado em Educação: Currículo) - Pontifícia Universidade Católica de São Paulo, São Paulo, 2019. Disponível em: https://tede2.pucsp.br/handle/handle/22278. Acesso em: 18 maio 2020.

UNESCO. Declaração Universal sobre a Diversidade Cultural. 2002. Disponível em: http://unesdoc.unesco.org/images/0012/001271/127160por.pdf. Acesso em: 28 mar. 2018.

UNESCO. Plano de ação - Programa Mundial para Educação em Direitos Humanos. Paris: Unesco, 2006.

VALENTIM, Daniela F. D. Educação intercultural crítica e ação afirmativa: avanços e desafios. In: CANDAU, Vera Maria (Org.). Interculturalizar, descolonizar, democratizar: uma educação "outra"? Rio de Janeiro: 7 Letras, 2016. p. 144-158. 


\title{
7 Lew \\ 1SSN: $1984-6444$

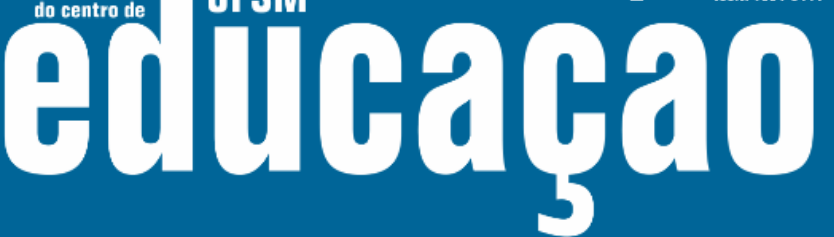

ISSN: 1984-6444 | http://dx.doi.org/10.5902/1984644444454

(C) $(1) \Theta$

This work is licensed under a Creative Commons Attribution-NonCommercial 4.0 International (CC BY-NC 4.0)

\section{Nota}

\begin{abstract}
${ }^{1}$ A trama conceitual é uma proposta metodológica empregada por Ana Maria Saul e Alexandre Saul (2014) a partir da articulação de conceitos freireanos. Ela é trabalhada na Cátedra Paulo Freire, da PUC-SP desde o ano de 2001, sob a coordenação da professora Ana Maria Saul. A trama consiste numa explicitação esquemática de articulações vinculadas a um conceito central, como ponto norteador de uma reflexão.
\end{abstract}

